\title{
Community Health Global Network: "Clustering” Together to Increase the Impact of Community Led Health and Development
}

\author{
Marianne Safe ${ }^{\mathrm{a}}$, Nathan Grills $\mathrm{s}^{\mathrm{b}}$ Elizabeth Wainwright ${ }^{\mathrm{c}}$, Ted Lankester ${ }^{\mathrm{d}}$ \\ ${ }^{a}$ MBBS, Nossal Institute of Global Health, University of Melbourne, Victoria, Australia \\ ${ }^{b}$ MBBS, MPH, DPhil, Nossal Institute of Global Health, University of Melbourne, Victoria, Australia \\ ${ }^{c}$ MSc, NCTA, Managing Director, Community Health Global Network, London, UK \\ ${ }^{d}$ MA, MB, BChir, MRCGP, FFTM, RCPSGlasg, Community Health Global Network, London, UK
}

\begin{abstract}
Background: Community Health Global Network (CHGN) is a collaborative network, founded to strengthen collaboration between community-based health programs many of which are faith based initiatives. It seeks to address this in two ways: through its global network of players in community health and in the formation of "Clusters." CHGN Clusters are networks of community health programmes and individuals in specific geographical locations. This case report outlines the formation of the Kenya Cluster.

Aims: To describe the steps in the formation of the Kenya Cluster and to outline the primary outcomes and potential impact of the network. To discuss how learning from the Kenya Cluster may assist other established Clusters and the initiation of new Clusters.

Method: Information for this case report was gained from meetings and consultations with various individuals including leaders and members of the Kenya Cluster, other national community health experts, CHGN International staff and advisors to CHGN Uttarakhand Cluster in India. In addition, information was gained from personal observation during in-country field work.

Results: The Kenya Cluster is emerging as a platform for community health programs to connect and network. These connections have led to transfer of information through stories, best practice, training, contacts and opportunities amongst Cluster members. The Cluster has also established links with government and multilaterals enabling greater access to support at the community level.

Conclusions: There is early indication that the formation of the Kenya Cluster is supportive of the Cluster model as a unique way of strengthening collaboration between community health programs. Clusters have the potential to improve the link between faith-inspired initiatives and secular and multilateral development organisations. Lessons from the Kenya Cluster can progress the development of other Clusters. Further evaluation will be conducted to assess the impact of the Kenya Cluster and the overall impact of the Cluster approach.
\end{abstract}

Nov 2014. Christian Journal for Global Health, 1(2):71-80. 


\section{Introduction}

One of the key barriers to universal health coverage is multiple actors poorly coordinated. ${ }^{1}$ To counteract this weakness in global health, there is growing evidence that networking and intentional collaboration between community health programs can improve service delivery and promote greater impact. ${ }^{2,3}$

A number of terms are used in the literature to describe the ways community health programs can work together. Agranoff and McGuire define networks as "the process of facilitating and operating in multi-organisational arrangements to solve problems that cannot be solved, or easily solved, by a single organisation." ${ }^{4}$ The terms consortia and collaborative are typically used to describe similar organizations that benefit more from collective actions than as individual players. The term coalition tends to refer to groups of different organizations whose interests converge or overlap but who have separate agendas and interests. Collaboration usually implies a closer working together and is often more intentional. ${ }^{5,6}$

Community Health Global Network (CHGN) was founded in 2005 in response to a perceived lack of collaboration between community-based health programs and initiatives. CHGN works in two ways: 1) Through a global network of over 700 community health workers (CHWs), programme managers, policy makers, faith-leaders, academics, students and others using this platform to circulate information, training, stories and expertise through regular bulletins, a website and social media and 2) through local community-centred movements or "Clusters" of people and programmes involved in the diverse social determinants of community health.

Clusters have been established in India, Bangladesh, Zambia and Kenya and are emerging in other countries including Myanmar (Burma). This article describes the formation of the Kenya Cluster including its outcomes and potential im- pact, and how experience gained can progress the development of other Clusters.

\section{The Cluster Model}

According to observations by community health expert and CHGN's co-founder, Dr Ted Lankester,

In any given area there were many small, struggling health programmes, mostly funded by outsiders, each doing their own thing ... they are often not linked with other charities or local government services and usually unaware that 10 miles down the track another group are doing almost exactly the same thing for the population they are serving. In areas of great need there is overlap, competition, and ineffective coordination of NGOs and other healthcare organisations. (personal communication, Feb 2013)

Through its global network and local movement through Clusters, CHGN aims to connect health initiatives, ensure they are appropriately informed and increase their influence and impact on a local, national and international scale. CHGN Clusters are groups of community health programmes and individuals in specific geographical locations. Representatives of programmes, as well as community health workers, faith leaders, community leaders and others, seek to collaborate on mutually agreed activities with the vision of improving health and well-being in the areas where they live and work.

CHGN has developed the "Connect, Inform, Influence" concept to facilitate the Cluster development process (Figure 1). The intention is that Cluster members focus on trust- building and connection, resulting in both mutual encouragement and effective collaboration. These connections can lead to transfer of information - through stories, best practice, training, contacts and opportunities amongst Cluster members and beyond. The Cluster has the potential to become the 
"go-to" source for those involved in community health learning and action in the region where it operates. This enables the government and other actors to engage with one authentic voice from that community. Through this process the Cluster model can begin to influence health policy at a regional level (as seen in the CHGN Uttarakhand Cluster). In turn this contributes to the strength- ening of health systems, a priority in global health. We believe the Cluster model is distinctive from other collaborative initiatives. The collaboration is 'bottom-up' in that the Clusters themselves define their operating principles, membership, agenda and action plans. It allows for highlighting local strengths and resources and helps grass roots responses to issues.

Figure 1: CJGH focuses on three key themes as a guide for Cluster formation, growth and impact.

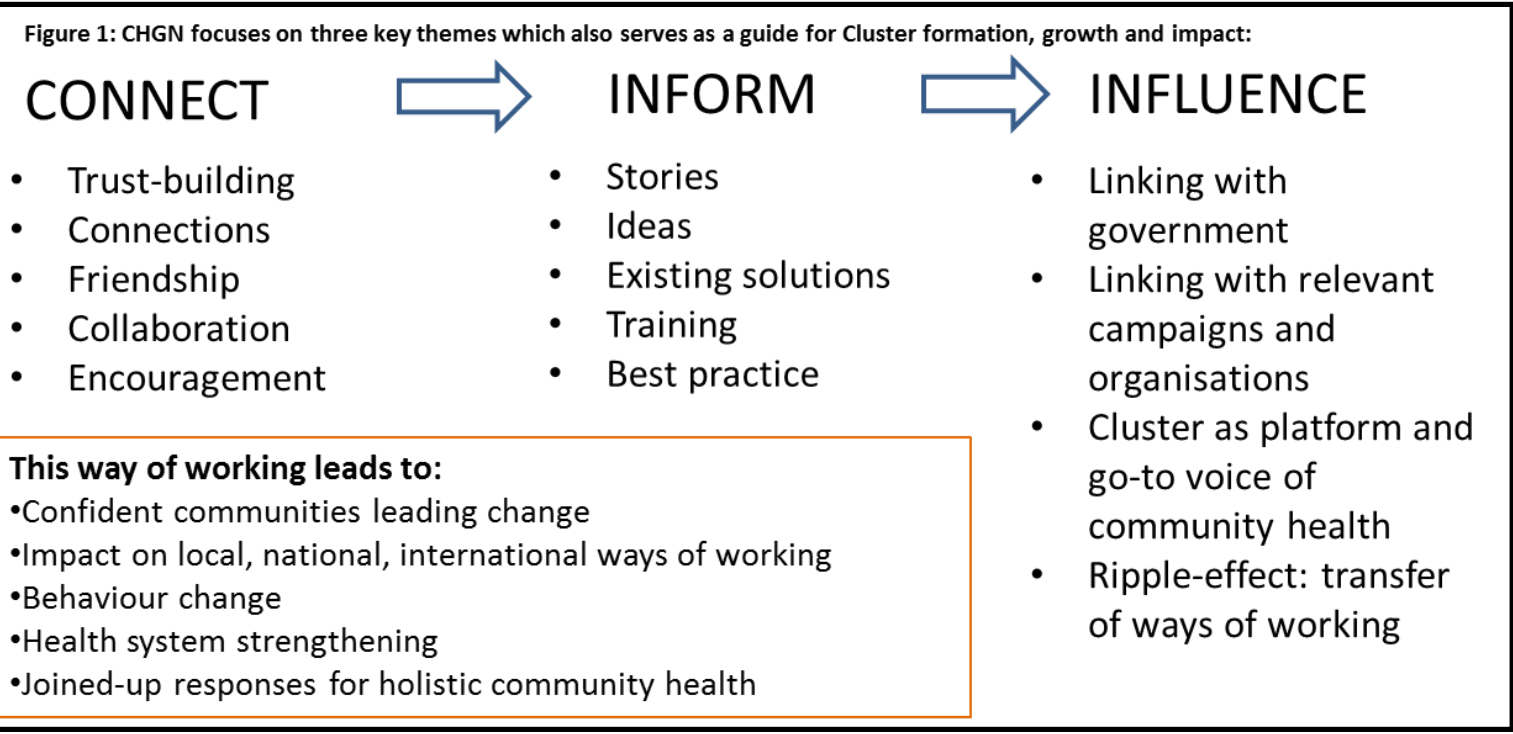

\section{Rationale for a Kenya Cluster}

According to the Kenyan Ministry of Health, "A large proportion of Kenyans continue to carry one of the highest preventable burdens of ill health in the world. Much of this burden can be lifted and prevented with existing knowledge and resources."7 Why is this still the case despite the abundance of development agencies in Kenya? Sylvia Ngatia, a missionary public health officer, believes that local programmes need to be working together effectively to have an impact: "If we truly want to help the community, why don't we hold hands?" (Personal communication, April 2013) A leader in an international child health organisation commented similarly: "This is why we need to network. We can be working on the ground in our own corners and we may not realize an expert is close by." (personal communication, Viva International, April 2013) Conse- quently, there has been a growing desire for a platform to share ideas, resources and training, and to avoid overlap and duplication. With these principles in mind CHGN was invited by leaders of community health programmes to seed a Cluster in order to decrease programme isolation and promote connectedness.

\section{Formation of the Kenya Cluster Pre-Cluster Launch Visits}

Prior to the Cluster launch CHGN staff and associates visited Kenya and met with key individuals who would act as potential Cluster champions. Two separate nationals had heard of the Cluster concept by word of mouth and the CHGN website and invited CHGN staff to visit their communities. Communication between CHGN and these nationals continued and an initial two 
week visit was followed up with a two month stay by a CHGN staff member. These visits involved outlining the Cluster vision and potential, identifying participants and exploring the wide variety of benefits. The time taken in developing trust and relationships has proven to be vital to the Cluster model. In the analysis of the Uttarakhand Cluster by Grills et al, the key pioneers are referred to as "brokers" and were found to be "crucial in network formation." . A similar pattern emerged in Kenya. It was important that CHGN associates stayed within the community and, if invited, lived with the potential members. This often involved travelling to remote areas. When discussing ways to build and sustain the Cluster, one member, speaking to the CHGN staff, said, "we value your opinion on this, you've been here, lived with us and see how we work and now we have built trust." (personal communication, Mathew Owili, Education and Health manager, World Vision Kolowa, Oct 2013)

\section{Coming alongside local change-makers and champions}

Three key champions were identified on the basis of being trusted by their communities and linked to either government or local universities. CHGN staff built relationships with these members, listened to their vision for a Cluster in the region and brought them together. The champions also acted as connectors and networkers. Identifying key champions who were respected and trusted members of their communities encouraged and motivated others to join the emerging Cluster. ${ }^{3}$ These champions and CHGN staff met with a large cross-section of people of various programmes to discuss if and how they would benefit from being part of a Cluster and to invite them to the Cluster Seminar.

\section{Cluster Seminar and Launch}

In May 2013, a five-day planning seminar was held and this culminated in the launch of the CHGN Kenya Cluster. Over 30 community health workers, representatives of community programmes, faith leaders, community leaders, local and district government officials and university representatives from the Tropical Institute of Community Health and Development gathered together to share personal experiences and jointly determine priority areas.

The "Connect, Inform, Influence" themes developed by CHGN to facilitate the Cluster process were introduced at the seminar. Members used a self-assessment tool (provided by Affirm Associates) to analyse their current situation within these themes, and to develop their vision for moving forward. They also shared existing concerns and explored appropriate regional solutions. A significant proportion of the seminar was facilitated by the Cluster champions. This increased local ownership and relevance. Towards the end of the launch, a leadership team was elected by the members to progress the vision.

\section{SALT Methodology}

CHGN worked with Affirm Associates to introduce the "SALT" methodology during the seminar. SALT is a widely used way of working based on identifying the strengths and assets of community members. It focusses on encouraging and measuring the way in which individuals and communities respond with hope and enthusiasm to shared challenges. SALT is a mnemonic for Stimulate, Appreciate, Learn and Transfer. It is practised during household or neighbourhood visits, encouraging facilitators to be "learners" rather than "teachers" in order to identify strengths and concerns within a community. By identifying strengths at a household level these solutions can be transferred household to household to create a community movement and a locally relevant shared response to various issues (Figure 2). ${ }^{8}$ 
Figure 2: Use of SALT to stimulate community conversation at local level

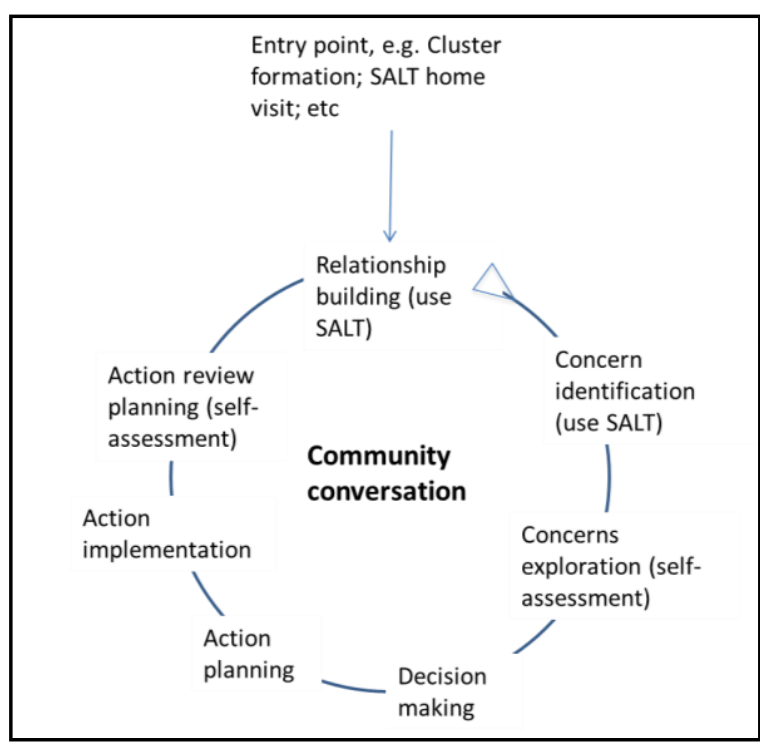

During the Cluster seminar, members conducted SALT visits in nearby households. This was a clear way of demonstrating how connections could be made, how neighbourhood strengths and concerns could be recognised and how "community owned" action plans could emerge.

Case study: tackling Female Genital Mutilation

JN is a CHW in East Pokot, North Rift, Kenya from the Pokot tribe. Using the SALT methodology which she learned about through the Cluster, the subject of female genital mutilation (FGM) was raised by the students during a secondary school visit. This was remarkable, in a place where FGM is widely practiced but rarely discussed. JN knows first-hand how the dangerous practice means girls are forced out of school and into early marriage. Around four fifths of girls who undergo FGM are not in school, or drop out of school afterwards. As a result of this encounter, JN has committed to regular visits with the school to encourage the girls to remain in school and prevent further FGM practices in the current generation. She hopes to continue to talk to the girls about existing solutions, and to support the girls in identifying and achieving their hopes and visions. She will link the concerns there with the work of the CHWs and with other community health initiatives in the region.

\section{Sub-Clusters}

One of the unique features of the Kenya cluster is the existence of sub-Clusters. Kenya Cluster leaders introduced sub-Clusters because members were spread geographically. This is referred to as low geographical homiphily in social network theory. ${ }^{3}$ The sub-Clusters helped provide geographically relevant connections, a platform for advocacy, mutual encouragement, and local communities of learning. Local sub-Clusters are represented in the larger Kenya Cluster, the platform where their voices could be heard (Figure 3).

\section{Ngoron Sub-Cluster}

Members of the Kenya Cluster from the relatively isolated area of Ngoron in East Pokot requested sub-Cluster facilitation in their area. This sub-Cluster facilitation was done by a national facilitator and CHGN international staff. Acknowledging the challenges faced by the community in accessing medical services, the sub-Cluster works together on community health programs based on the Kenyan Government's Community Health Strategy. ${ }^{7}$ This Strategy identifies the need for a holistic approach to community health, where physical health is not separated from other facets of wellbeing, such as socioeconomic development, spiritual beliefs and education. Therefore, the sub-Cluster has chosen to include the region's church, agricultural and school leaders to work together with community leaders, NGOs and health workers on the implementation of the community health programmes. 
Figure 3: CHGN Clusters. Arrows represent two-way sharing and learning

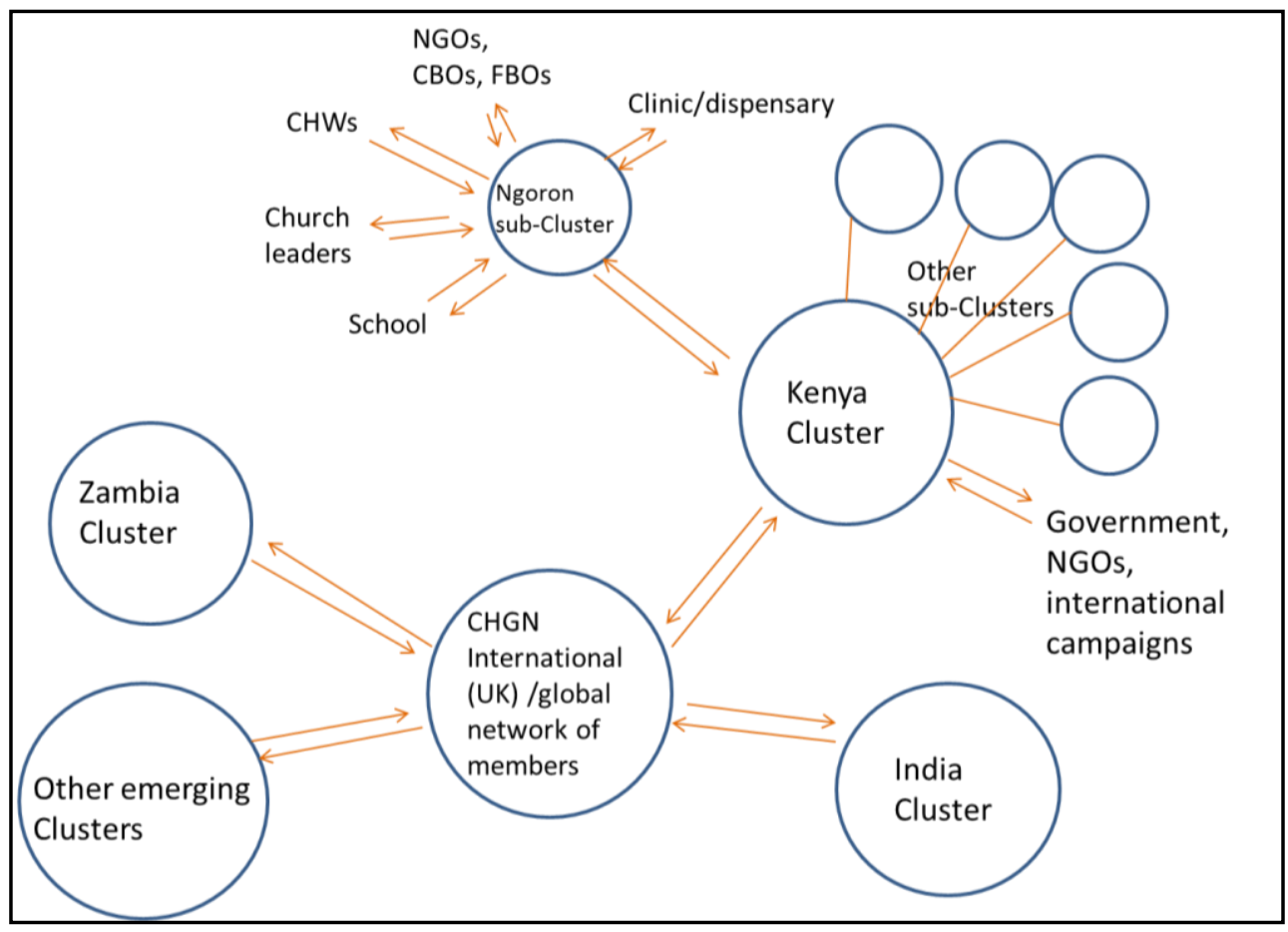

\section{Cluster Follow-up Meeting}

Six months after the launch of the Kenya Cluster, a meeting was held to consolidate and strengthen connections. Stories were shared, and SALT refresher training was given. Kenya Cluster leaders facilitated a discussion to develop draft vision and mission statements:

Draft vision: "To see holistically healthy and transformed communities."

Draft mission: "To provide a platform to connect, inform and influence for positive change in our communities."

Developing the vision and mission statements provided a foundation and general direction for the Cluster and increased the unity of the group. A list of common concerns was also developed which included sanitation, community health worker provision, malaria, HIV, connectedness and farming/irrigation. These concerns will provide a framework for future training meetings and collaborative Cluster projects.

Cluster members also initiated a communal Cluster fund by each making a small contribu- tion. CHGN contributed hospitality for the initial Cluster seminar and some subsidy for accommodation during the seminar. The Cluster's leadership team directed current Cluster activities and goals. They worked with the CHGN international team who facilitated, supported, signposted, offered solutions and links, and disseminated information or trainings.

\section{Outcomes}

The initial outcomes noted within the Kenya Cluster fit within the concept areas of "Connect, Inform and Influence."

\section{Connect}

The Kenya Cluster is being used for networking between community-based organisations, pastors, health workers, Non-Governmental Organisations, the University sector and the Government. The Cluster has put together a member directory, with information about roles and areas of knowledge. As an example, the Kenya Cluster has linked a health worker in East Pokot to the 
other members in the region. He is now assisting these members by providing immunisations to their community health programs. Other members have plans to assist him with community health worker training.

Connections through the Kenya Cluster are facilitating links between faith based organisations, secular development agencies, and the government. Kenyan community health professor Charles Wafula comments: "Why is it we have good scientific health systems but when it comes to social implementation we fail? What is the missing link? So much has been invested in Africa but the health outcomes are still poor - is the African man trapped? And if so by what?"9 Among others, he believes one "missing link" is the addressing of African traditional beliefs within communities.

Through the Cluster the Tropical Institute of Community Health, the Africa Gospel Church, the Community Health Empowerment (CHE) program and the Government are planning to work together to implement aspects of the community health strategy. In addition, the various ways through which African traditional beliefs can affect health will be addressed. There are plans for the university to monitor the impact of this unique approach.

In addition, recognition and appreciation from both community and colleagues is cited as a key factor in motivating and retaining health workers, sometimes over financial incentives. ${ }^{10}$ Similarly, many Cluster members explained the benefits of connecting with those doing similar work and having their own work recognised. Those working in remote areas emphasised that this motivated and encouraged them to continue in their workplace despite various hardships.

\section{Inform}

The Cluster model in Kenya is being used to inform its members at various levels:

- Cluster members have been sharing stories, ideas and information with each other.
- CHGN staff have shared stories and learning from the Uttarakhand Cluster in North India, showing the value of global crosslearning.

- The Cluster forum will be used for training on thematic topic areas like irrigation and malaria, but also to share ways of working such as use of the SALT methodology.

- A toolkit of resources (e.g. best practices, fundraising, communication tools) is being compiled by CHGN. Members will be able to access the relevant tools both through Cluster meetings and online.

\section{Influence}

Existing multilateral organisations in Kenya, such as the World Health Organisation (WHO), have both direct and indirect engagement with community-based health initiatives. Conversely, faith-based, NGO-related and community-based CHW programmes often have their own arrangements for health workers. Therefore, it is not uncommon for there to be barriers to communication between these two sectors. ${ }^{11,12}$ With this in mind, the Cluster as a collective provides a representational focus for the government and multilaterals to engage with civil society organisations at local and district levels. For example, the Cluster has established links with the Ministry of Health, the international One Million Community Health Workers Campaign (see below), and with the University sector, enabling greater support to be available at the community level.

A prominent example of the Kenya Cluster's current influence is through their involvement in the One Million Community Health Workers Campaign, an initiative of the United Nations Sustainable Development Solutions Network and the Earth Institute of Colombia University. This campaign seeks to train and support increased numbers of CHWs across SubSaharan Africa. ${ }^{13,14} \mathrm{CHGN}$ is on the steering council for the campaign at an international level, and is linked with the campaign in-country, 
through the Kenya Cluster. There is much enthusiasm amongst Cluster members as the need for CHWs was identified as a Cluster priority. The Cluster feels their involvement can ensure the campaign reaches areas of need. The link is also meeting the Campaign's intention to build on systems and initiatives which are already established.

\section{Challenges}

The Cluster includes diverse members from diverse organisations and, as expected, there were preconceived ideas about how CHGN would operate. Some prospective members presumed that attending the launch would lead to direct financial benefits to their program. Others presumed that CHGN would be rolling out a program according to its own agenda rather than accompanying and connecting established programs. Time was taken to correct such mis-preconceptions.

Unlike other Clusters, the Kenya Cluster is geographically wide-spread. This presented some logistical challenges regarding travel distances and cost and these issues may alter the frequency of future full Cluster meetings. Prospective members from various remote areas were invited intentionally in order to include those who were relatively isolated. Despite this challenge, it is hoped that specific outcomes will be addressed at sub-Cluster level and the national Cluster will be used as a platform for strategic discussion and amplifying voices for important needs and challenges.

\section{Lessons and Recommendations}

1. Trust and relationships were key to the Cluster formation and time should be taken to build these when initiating future Clusters.

2. A Cluster model can link primary health care programs working at the community level to larger, more traditional vertical programs e.g. national and international antimalaria or HIV programs. These smaller community led initiatives can become part of or stimulate a larger community movement, ultimately increasing the impact of the vertical programs.

3. A Cluster can represent members of different disciplines of community health. Over time, it can become a platform to address locally relevant social determinants of health. The importance of such holistic approaches to healthcare has been highlighted in the Lancet and London International Development Centre Commission's analysis of the Millennium Development Goals. This analysis emphasized the need for, "local interventions in poverty reduction, health, education, and gender equality coming together for the same groups of people," when setting goals post $2015 .^{11}$

4. Only minimal start-up funds were provided in the formation of the Kenya Cluster. This has encouraged the members themselves to contribute financially and in directing the Cluster. Such an approach seems to promote local ownership and contributes to such a network becoming self-sustaining.

5. It is reported that $40 \%$ of Kenya's health service is provided by affiliates of the Christian Health Association of Kenya (CHAK) and Kenya Episcopal Conference (KEC). ${ }^{15}$ A Cluster can be used, as is the case in Kenya, to better understand the role of faithinspired initiatives and improve their linkage with secular and multilateral development organisations. There is opportunity for both groups to come together to share ways of working and best practices, and CHGN will feed into this dialogue using learning that is coming from local community movements, and from the global network. CHGN is founded on Christian values and beliefs, and on humanitarian principles, and is inclusively open to all those who are committed to making the world a healthier, better and fairer place. 


\section{Conclusion}

The recently formed Kenya Cluster of CHGN is emerging as a well-connected and informed platform that can support specific and tangible priorities in different regions through its sub-Clusters. The Cluster will continue to be accompanied and supported and its impact will be monitored. Lessons learnt can be taken from the Kenya Cluster to bring new ideas to other established Clusters and also to inform the initiation of new clusters. In 2015, members from three Clusters will meet for further sharing and analysis of both community response and the overall impact of the Cluster approach.

\section{References}

1. Tulenko K, et al. Community health workers for universal health-care coverage: from fragmentation to synergy. Bull World Health Organ. 2013; 91:847-852. http://dx.doi.org/10.2471/BLT.13.118745

2. Grills NJ, Porter G. Networking between community health programs: A team-work approach to improving health service provision. BMC Health Services 2013 (under review).

3. Grills NJ, et al. Networking for health: the Uttarakhand Case Study BMC Health Services 2013;12:206

4. Agranoff, R, McGuire M. Collaborative Public Management: New Strategies for Local Governments. 2003. Washington, DC: Georgetown University Press.

5. Kegler $\mathrm{M}$ et al. How does community context influence coalitions in the formation stage? A multiple case study based on the Community Coalition Action Theory. 2010. BMC Public Health, 10:90. http://dx.doi.org/10.1186/1471-2458-10-90

6. Kendall $\mathrm{E}$ et al. Collaborative Capacity Buidling in Complex Community-Based Health Partnerships: A Model for Translating Knowledge into Action. 2012, 18(5).

7. Kenya Ministry of Health. Taking the Kenya Essential Package for Health to the Community: A Strat- egy for the Delivery of LEVEL ONE SERVICES. Ministry of Health- Health Sector Reform Secretariat 2006.

8. Salt Approach [Internet]. Community Life Competence; [Updated 2012; cited 2013 Jan 20]. Available from

http://www.communitylifecompetence.org/en/pages/3 5-salt-approach

9. Wafula C. Plenary: Outcomes of the implementation of the Kenyan Community Health Strategy. Presented at: Tropical Institute Community Health and Development Annual Scientific Conference; 2013 April 29-May 2; Kisumu, Kenya.

10. Willis-Shattuck M, et al. Motivation and retention of health workers in developing countries: a systematic review. BMC Health Services Research. 2008; 8:247 http://dx.doi.org/10.1186/1472-6963-8-247

11. Waage J, et al. Lancet and London International Development Centre Commission- The Millennium Development Goals: a cross-sectoral analysis and principles for goal setting after 2015. The Lancet. 2010; 376: 991-1023. http://dx.doi.org/10.1016/S0140-6736(10)61196-8

12. Grills NJ. The paradox of multilateral organisations engaging with faith based organisations. Global Governance. 2009; 15(4):505-520.

13. Singh P, Sachs JD. 1 million community health workers in sub-Saharan Africa by 2015. The Lancet. 2013; 382:363-365. http://dx.doi.org/10.1016/S01406736(12)62002-9

14. One Million Community Health Workers Campaign. [updated 2014 Jan 17, cited 2014 Jan18]. Available from: http://1 millionhealthworkers.org/

15. A Key Piece of the Puzzle: Faith-Based Health Services in Sub-Saharan Africa [Internet]. USAID; [updated 2007 Dec, cited 2014 Jan 18]. Available from:

http://www.capacityproject.org/index.php?option=com content\&task=view\&id=233\&Itemid=108 
Peer Reviewed

Competing Interests: None declared.

Supporting Agencies: Nick Henwood, CHGN; Ian Campbell, Affirm Associates; Gillian Porter, Nossal Institute of Global Health.

Correspondence: Marianne Safe, Nossal Institute of Global Health, Melbourne, Australia. mazsafe@hotmail.com For more information and to become a CHGN member please visit www.chgn.org

Cite this article as: Safe MA, Grills N, Wainwright E, Lankester T. Community Health Global Network: "Clustering" together to increase the impact of community led health and development. Christian Journal for Global Health (November 2014), 1(2):71-80. http://dx.doi.org/10.15566/cjgh.v1i2.9

(C) Safe MA, et al. This is an open-access article distributed under the terms of the Creative Commons Attribution License, which permits unrestricted use, distribution, and reproduction in any medium, provided the original author and source are properly cited. To view a copy of the license, visit http://creativecommons.org/licenses/by/3.0/

www.cjgh.org

Nov 2014. Christian Journal for Global Health, 1(2):71-80. 